\title{
Corrosion resistance of porous ferritic stainless steel produced by liquid metal dealloying of Incoloy 800
}

\author{
Morgane Mokhtari ${ }^{\mathrm{a}} \mathrm{b}, \mathrm{c}$, Takeshi Wada ${ }^{\mathrm{a}}$, Christophe Le Bourlot ${ }^{\mathrm{b}}$, Jannick Duchet-Rumeau ${ }^{\mathrm{c}}$, \\ Hidemi Kato $^{\mathrm{a}}$, Eric Maire ${ }^{\mathrm{b}}$, Nicolas Mary ${ }^{\mathrm{b}, \mathrm{d}, *}$ \\ a Institute for Materials Research, Tohoku University, Sendai 980-8577, Japan \\ ${ }^{\mathrm{b}}$ MATEIS Laboratory, Lyon University, Villeurbanne 69100, France \\ ${ }^{\mathrm{c}}$ IMP Laboratory, Lyon University, Villeurbanne 69100, France

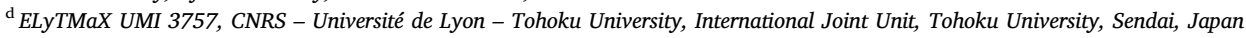

\section{A R T I C L E I N F O}

\section{Keywords:}

Dealloying

Nickel-based superalloy

Porous material

Corrosion resistance

Iron alloys

\begin{abstract}
A B S T R A C T
Liquid metal dealloying is a newly available technology used to create bulk porous materials. In this study, a commercial nickel-based superalloy, Incoloy 800, was dealloyed to elaborate a fully porous ferritic stainless steel. The Mg selective dissolution in nitric acid solution acts as a passivation treatment that enhances the passive film resistance.

Corrosion tests confirm the beneficial effect of the nitric acid treatment on the Cr enrichment of the passive film thus improved the material resistance. The electrochemical characterizations show a higher effect of the size porosities on the diffusion kinetics of the electrolyte rather than on the pitting sensitivity.
\end{abstract}

\section{Introduction}

Porous bulk materials, and especially nanoporous metals, have attracted considerable attention owing to their excellent functional properties, including their high catalytic activities, sensing capabilities, and surface-enhanced Raman scattering resulting from their interconnected structure and high specific surface area [1-4]. More recently, micro/nanoporous materials have been applied as biomaterials [5-10]. In most of the cases, materials with the smallest ligament size and the highest specific surface area are required. Also, the design (i.e., morphology) of ligaments must be controlled to optimize the microfluidic flow and to ensure the mechanical stability of the samples [11]. Such porous structures are usually produced by molten metal foaming or metal particle sintering at the industrial scale. However, the formation of connected sub-micron pores is difficult to obtain with these techniques [12,13]. Electro-spinning, self-assembly and inject printing give fine microstructures, however they are slow processes with post treatment as sintering or carbonization materials to stabilize the porosity network. Note that the control of the porosity size over large scales is also not easy [12,14-16]. Alternatively, chemical or electrochemical dealloying are suitable for macroscopic scaled nanoporous samples with a controlled unimodal pore distribution. These techniques were initially applied to metals with noble elements such as $\mathrm{Au}, \mathrm{Ag}, \mathrm{Pt}, \mathrm{Pd}$,
$\mathrm{Cu}$ and $\mathrm{Ni}$ [4,17-23]. Chemical dealloying consists on a selective dissolution of metals from binary alloy in various acids and bases solution with a control of the temperature [24,25]. In some cases, hydrogen generation is reported during chemical and electrochemical dealloying that later affects the mechanical properties of the porous material [26]. Unlike chemical dealloying, liquid metal dealloying (LMD) can be used to prepare submicron-scale porous samples with less noble metals including $\mathrm{Ti}, \mathrm{Fe}, \mathrm{Cr}, \mathrm{Nb}, \mathrm{Mg}$ [27-30] while limiting secondary reactions in the solution, as hydrogen evolution.

LMD involves selective dissolution of one of the major elements of a solid precursor alloy in a liquid metal at few hundred degrees. Because the chemical composition of the material changes with the immersion time, atomic reorganization of the matter occurs, leading to the fabrication of a new material. In parallel, the metal bath is enriched into the dissolved element. LMD mainly works via chemical interaction among elements, which is governed by their enthalpies of mixing $\Delta H_{\text {mix }}$ $[27,31]$. To better understand the mechanism of dealloying, LMD was initially applied on model precursors. For example, Wada et al. [28] created a ferritic stainless steel foam (i.e., Fe-Cr-based alloy) by applying LMD to $\mathrm{Fe}-\mathrm{Cr}-\mathrm{Ni}$ alloy precursor. In this example, Ni was the sacrificial element selectively dissolved in a liquid Mg bath. Artymowicz et al. accessed to total dealloying of a precursor, leading to porous bulk material for the concentration of the sacrificial element $(\mathrm{Ni})$ in the 
precursor over the parting limit, approximately 20-25 at.\% for facecentered-cubic (FCC)/body-centered-cubic (BCC) lattice precursors [32]. In these previous examples, the final volume fraction of pores is predicted by the initial precursor composition alone, independent of the dealloying conditions [33,34]. However, the temperature of the liquid metal has an exponential effect on the ligament size and an increase of the dealloying time favors the coarsening of ligaments $[28,35]$.

As labmade precursors are expensive and usually produced in low quantity, the use of commercial alloys is under consideration for the industrialization of LMD. In a previous work [36], the LMD process was successfully applied to a commercial Incoloy 825 . The dealloyed material exhibited a porous structure highly dependent on the dealloying temperature as predicted by the literature. However, it was shown that the pore distribution was not necessarily unimodal. The results proved the feasibility of LMD on commercial material and also highlighted the good corrosion resistance of the porous materials [37,38]. However, a lack of control of the pore size with Incoloy 825 was pointed out. In conventional metallurgy, the microstructure and the presence of inclusions or precipitates strongly depend of the chemical nature of the alloying elements [39]. Based on that idea, a lower alloyed Incoloy was selected since this may reduce the number of chemical interactions between elements during LMD. Compared to Incoloy 825, Incoloy 800 (UNS N08800) does not contain copper among others [40,41]. Copper is known to form a solid solution with $\mathrm{Ni}$ and might play a negative role during LMD in term of porosity size control. Table 1 compares the mixing enthalpies for the main elements in a commercial Incoloy 800. Note that the exact chemical composition of our coupons will be determined by SEM-EDS later. Like Incoloy 825, a stainless-steel foam can be produced by LMD in a Mg bath from Incoloy 800 . Therefore, the objectives of the current study is (i) to elaborate a fully porous Fe-Crbased alloy with two different pores and ligament sizes, (ii) to discuss the role of the dissolution of the Mg-Ni phase in nitric acid solution on the corrosion resistance of the foam and (iii) to link the pore size on the electrochemical behavior of the final product. Note that the material resulting to the LMD will be named porous materials or metallic foam.

\section{Materials and methods}

\subsection{Materials synthesis}

A $1.57 \mathrm{~mm}$ thick Incoloy 800 sheet was provided by Nilaco (Japan) and cold-rolled until $1 \mathrm{~mm}$ thickness. Coupons of $30 \times 20 \mathrm{~mm}^{2}$ were extracted and no additional heat treatment was applied before LMD. Chemical compositions of coupons were determined by EDS-SEM and are given in the results section.

In LMD, the dealloying time and temperature are the two parameters that determine the theoretical ligament thickness and the dealloyed layer thickness [28,36]. In this work, Incoloy 800 coupons were immersed for $1 \mathrm{~h}$ in liquid $\mathrm{Mg}$ bath either at $750^{\circ} \mathrm{C}$ or $830^{\circ} \mathrm{C}$. A preliminary work shown that a dealloyed structure was obtained into the volume of the coupon before $1 \mathrm{~h}$. In order to insure homogeneous ligament size, LMD was performed during $1 \mathrm{~h}$. The lowest temperature was selected from the minimum of temperature required to initiate the dealloying process. For Incoloy precursor, this occurs above $750{ }^{\circ} \mathrm{C}$ $[29,36]$. The highest temperature was selected from our previous works dealing with dealloying of Incoloy 825 and labmade $\mathrm{Fe}-\mathrm{Ni}-\mathrm{Cr}$ precursor [34]. After air quenching at room temperature, a bicontinuous

Table 1

Mixing enthalpies of the major alloying elements in Incoloy 800 with $\mathrm{Mg}$, $\Delta \mathrm{H}_{\text {mix, Mg-M }}$ (after $\left.[31,42]\right)$.

\begin{tabular}{llllll}
\hline Element & $\mathrm{Fe}$ & $\mathrm{Cr}$ & $\mathrm{Ti}$ & $\mathrm{Si}$ & $\mathrm{Ni}$ \\
\hline Composition at.\% & $>38$ & $20-25$ & $<0.5$ & $<1$ & $28-34$ \\
$\Delta H_{\text {mix }} \mathrm{Mg}-\mathrm{M} / \mathrm{kJ} \mathrm{mol}^{-1}$ & +18 & +24 & +16 & -26 & -4 \\
\hline
\end{tabular}

microstructure was obtained with a matrix enriched in iron and chromium and a second phase of magnesium and nickel magnesium intermetallic compound. Then, the Mg-rich phase was chemically etched in a $3 \mathrm{M} \mathrm{HNO}_{3}(\mathrm{pH}-0.9)$ aerated aqueous solution for $16 \mathrm{~h}$ at room temperature (optimized treatment time). This last step finally reveals the metallic foam with an interconnected network of stainless steel ligaments.

For corrosion tests, stainless-steel ingots were also prepared from pure materials by arc melting with the same compositions as the porous samples as described in [28]. The ingots were cast into $8 \mathrm{~mm}$ diameter rods and surfaces were polished until $1200 \mathrm{SiC}$ grit paper. These samples were used as dense materials in order to better understand the role of porosities on the electrochemical behavior of porous samples

\subsection{Materials characterizations}

The cross-sectional and surface morphologies of the precursor, the bicontinous structure and porous samples were investigated by scanning electron microscope (SEM; Carl Zeiss ULTRA 55, Oberkochen, Germany). An Ar ion beam polisher was used to prepare cross-sections of samples (EM-3500 Hitachi, Japan). This method was preferred to classical cross section preparation in resin to limit the deformation of the ligaments during the several polishing steps. Quantification of the pore size was done from SEM images with Fiji image analysis software [43]. Note that these observations are representative of the porous microstructure since the microstructure does not evolve significantly after the chemical dissolution of the Mg-Ni phase [44].

Crystallographic structures of precursors and porous materials were defined by X-ray diffraction (XRD; Rigaku Ultima IV, Tokyo, Japan) using $\mathrm{Cu} \mathrm{K} \alpha$ radiation $(1.54 \AA$ A). Diffractograms were recorded in air at room temperature from $20^{\circ}$ to $100^{\circ}(2 \theta)$ using a step size of $0.005^{\circ}$. Experimental peak positions were compared to the open crystallography database (COD).

Surface chemistry of the porous surfaces were studied by X-ray photoelectron spectroscopy (XPS). The XPS spectra were recorded using a Versaprobe II PHI 5000 apparatus operated in constant analyzer energy mode (CAE; pass energy of $117.4 \mathrm{eV}$ for wide scan and $58.7 \mathrm{eV}$ for regions) with a monochromatized $\mathrm{Al} \mathrm{K \alpha}$ source $(1486.7 \mathrm{eV})$. The pressure of the chamber was maintained to less than $10^{-7} \mathrm{~Pa}$ during the experiments. No sputter cleaning was performed before analysis. Spectra were acquired at $90^{\circ}$ and referenced to the adventitious $C 1 \mathrm{~s}$ set at $284.6 \mathrm{eV}$. High-resolution windows scans $(0.129 \mathrm{eV})$ were recorded on the major elements of the oxide film: O1 s (524-538 eV), Cr2p (568-582 eV), Fe2p (700-720 eV), and C1 s $(278-292 \mathrm{eV})$. Data (background subtraction and peak fitting) were processed using Origin software with a Shirley background and a Gaussian peak shape. The binding energies were compared to an open-access XPS database to identify the species present on the samples [45]. In the elaboration process, the bicontinuous microstructure is merged in a nitric acid solution. In addition to dissolve chemically the Mg-Ni phase, the acidic solution plays the role of a passivation treatment on the stainless steel ligaments formed during LMD. The consequences of a passivation treatment are characterized by an $\mathrm{Cr}$ enrichment in the passive film and a thicker oxide layer [46]. The former can be confirmed by Eq. (1) which quantifies the chromium ratio in the oxide layer, $(\mathrm{Cr})_{\text {ratio }}$ from XPS analysis. $\mathrm{Cr}_{\mathrm{ox}}$ and $\mathrm{Fe}_{\mathrm{ox}}$ correspond to the area of the $\mathrm{Cr}$ oxide peak and the Fe oxide peak, respectively (Eq. (1)).

$C r_{\text {ratio }}=\frac{C r_{o x}}{C r_{o x}+F e_{o x}}$

From XPS analysis, the passive film thickness $\left(\xi_{\text {ox }}\right)$ can be also estimated by Eq. (2). In this relation, the passive film thickness is supposed to be an oxide over-layer.

$\xi_{o x}=\lambda * \ln \left[1+\frac{I_{C r, o x}}{I_{C r, m e t}}\right]$ 
where $\lambda$ is the medium free path length for photo-electrons from $\mathrm{Cr}$. The common value of $1.7 \mathrm{~nm}$ is used in this work [46]. $\mathrm{I}_{\mathrm{Cr} \text {,ox }}$ and $\mathrm{I}_{\mathrm{Cr} \text {,met }}$ are the measured intensities on XPS curves of the chromium oxide and metal peaks, respectively.

Electrochemical characterizations were performed in a classical three-electrodes cell connected to a potentiostat (VP300, Biologic France). Working electrodes consisted on metallic samples. Potentials were measured versus the mercury-mercurous sulfate reference electrode (MSE) $\left(\mathrm{E}_{\mathrm{MSE}}=+0.65 \mathrm{~V} / \mathrm{SHE}\right)$. A platinum wire of $7.2 \mathrm{~cm}^{2}$ played the role of counter electrode. The experiments were performed at room temperature $(\sim 295 \mathrm{~K})$ in aerated and stagnant $0.1 \mathrm{M} \mathrm{NaCl}$ aqueous solution ( $\mathrm{pH}$ 6.5). Before immersion in the corrosive solution, the samples were stored in the laboratory atmosphere for 8 days to obtain a mature oxide film (relative humidity at $60 \%$, temperature at $25^{\circ} \mathrm{C}$ ). In solution, electrochemical measurements were performed as follow: (i) open-circuit potential (OCP) measurement for $2 \mathrm{~h}$, (ii) potentio electrochemical impedance spectroscopy (PEIS) measurements at the OCP in the frequency range of $100 \mathrm{kHz}$ to $30 \mathrm{mHz}$ with 9 points per decade using a $20 \mathrm{mV} / \mathrm{s}$ peak-to-peak sinusoidal voltage, and (iii) linear sweep voltammetry (LSV) measurements from $-0.20 \mathrm{~V}$ vs. OCP to $1.00 \mathrm{~V}$ vs. MSE at $1 \mathrm{mV} / \mathrm{s}$. All the measurements were performed at least two times. Because the deviation of the results was minimal, only one curve is provided for each measurement.

\section{Results and discussion}

\subsection{Precursor characterization}

SEM images of Incoloy 800 show a homogeneous microstructure with few heterogeneities randomly dispersed (Fig. 1). The chemical composition of Incoloy 800 is reported in Fig. 1(b). Nickel, Iron and Chromium concentrations are at 30.1 at.\%, 47.3 at.\%, and 21.2 at.\%, respectively. Two minor elements were also detected: $\mathrm{Si}$ at 0.8 at.\% and $\mathrm{Ti}$ at 0.8 at.\% EDS maps of the three major elements (i.e., Ni, Fe and $\mathrm{Cr}$ ) confirm the monophase microstructure without local enrichment. Distribution of two minor elements ( $\mathrm{Si}$ and $\mathrm{Ti}$ ) was also analyzed since they can form inclusions and later play a role in the dealloying process and pore size (Fig. 1(a)). Few Ti-rich inclusions of approximately $10 \mu \mathrm{m}$ in size were detected as observed otherwise for Incoloy 800 [40,41]. On XRD diagrams, the Incoloy matrix presents the expected FCC microstructure (Fig. 1(c)) and any Ti-based secondary phase was identified on XRD diagram suggesting a total volume of Ti-rich phase less than 1 vol. $\%$.

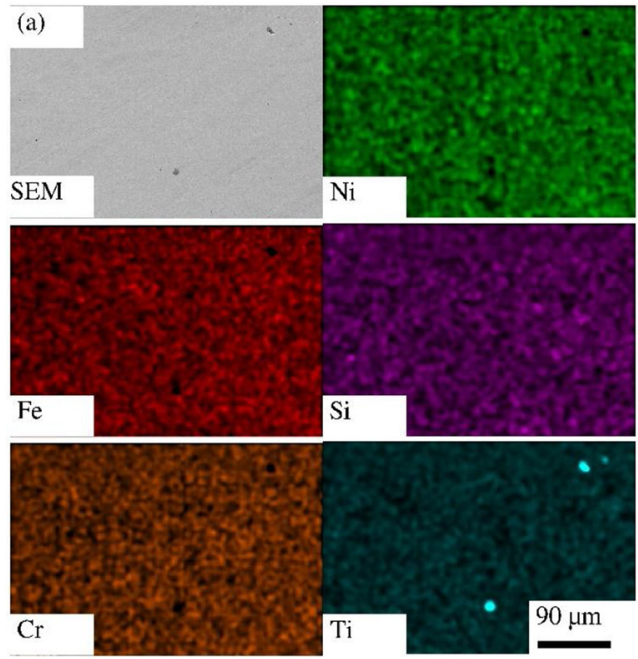

\subsection{Dealloyed microstructures}

Liquid Metal dealloying is a chemical process in liquid metal where the precursor losses a part of its matter. For the Incoloy 800, nickel dissolves in Mg bath during LMD. Consequently, a size reduction of the sample might be expected. In Fig. 2(a), the macroscopic appearance of samples before and after LMD are compared. Whatever the temperature of liquid $\mathrm{Mg}$ bath, the geometry of the sample is not modified while the size shrink is limited to $1 \%-3 \%$. On one hand, this indicates that the dealloying not drastically changes the apparent volume. On the other hand, this method allows to form porous material (i.e., lighter material) keeping the initial aspect of the material.

Fig. 2(b) shows the typical bicontinuous microstructure produced at $830^{\circ} \mathrm{C}$ with a homogeneous reparation of $\mathrm{Fe}$ and $\mathrm{Cr}$ in the ligaments. In the $\mathrm{Mg}$-Ni phase, the chemical composition is equivalent to the eutectic one [29]. Note that similar microstructure was observed at $750{ }^{\circ} \mathrm{C}$. A particular attention paid on Fig. 2(c) and (d) highlights the role the temperature on the size of ligaments. On one hand, this confirms that the chemical composition of minor alloying elements in the precursor plays a significant role on the ligament growth. On the other hand, the temperature of liquid $\mathrm{Mg}$ plays a determinant role in the characteristic length of the ligaments [28]. The volume fraction of pores (i.e., the $\mathrm{Mg}$ phase in dual phases microstructure) can be estimated from the grayscale difference between the stainless-steel ligaments and the $\mathrm{Mg}$ phase. Regardless of the microstructure, the porosity volume is at approximately $28 \% \pm 3 \%$, which is consistent with the theoretical porosity (29 \%) discussed in [34] for such kind of material. Fig. 2(b) and (c) show a reservoir shape for pores with only a modification of the dimension with the temperature of dealloying. The ligament thicknesses were evaluated from the SEM images using 2D granulometry [43]. This analysis is usually underestimating the ligament and pores sizes, therefore, a correction factor equal to $4 / \pi$ should be used to compare these values to $3 \mathrm{D}$ analysis [47]. Table 2 reports the average ligament and pore sizes measured after dealloying at $750{ }^{\circ} \mathrm{C}$ and $830^{\circ} \mathrm{C}$. After the chemical etching in nitric acid of the bicontinuous microstructure, the macroscopic aspect as well as the ligament design are not modified in the metallic foam [34]. SEM-EDX analysis (inset of Fig. 2(e)) confirms the chemical homogeneity of the ligaments in the volume of the sample $\left(\mathrm{Fe}_{67.7} \mathrm{Cr}_{29.5} \mathrm{Ti}_{1.0} \mathrm{Si}_{1.8}\right.$ (at.\%). Note that $\mathrm{Ni}$ and $\mathrm{Mg}$ contents were below the detection limit confirming the efficiency of the nitric acid treatment in the dissolution of $\mathrm{Mg}$-Ni phase. The atomic ratio of $\mathrm{Fe}$ to $\mathrm{Cr}$ in the porous sample is equal to 2.2 which is almost equal to that in the precursor $(\mathrm{Fe} / \mathrm{Cr}=2.3)$. Therefore, $\mathrm{Fe}$ and $\mathrm{Cr}$ atoms were fully preserved in the ligaments during dealloying and chemical treatment. The

(b)

\begin{tabular}{|c|c|c|c|c|c|}
\hline & $\mathrm{Fe}$ & $\mathrm{Cr}$ & $\mathrm{Ti}$ & $\mathrm{Si}$ & $\mathrm{Ni}$ \\
\hline at\% & 47.3 & 21.2 & 0.6 & 0.8 & 30.1 \\
\hline
\end{tabular}

(c)

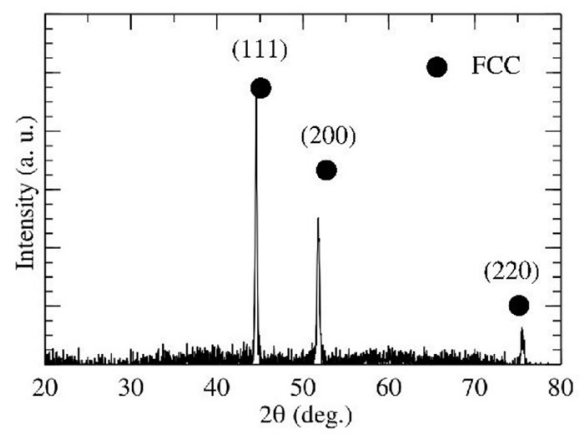

Fig. 1. (a) SEM micrograph of polished surface of Incoloy 800 (precursor sample) and elemental maps of Ni, Fe, Si, Cr, Ti. (b) Chemical composition analysis by EDX based on the previous list of elements and (c) XRD pattern of Incoloy 800 (precursor sample) with its austenitic phase. 
(a)
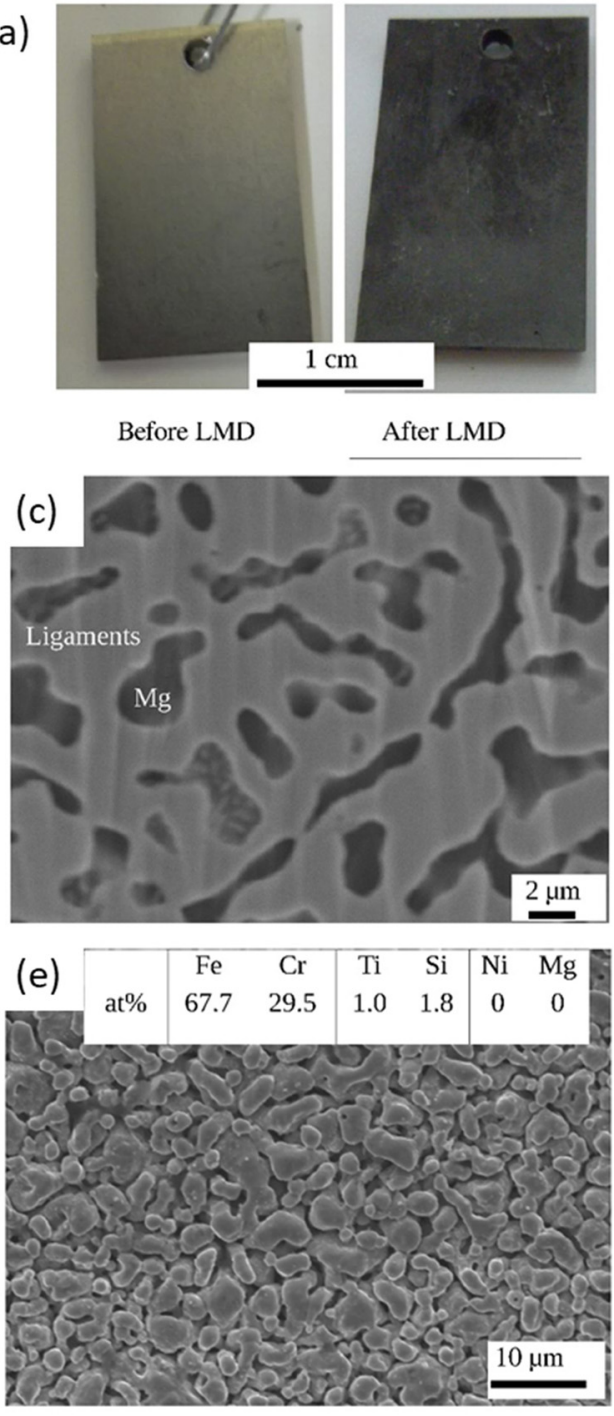
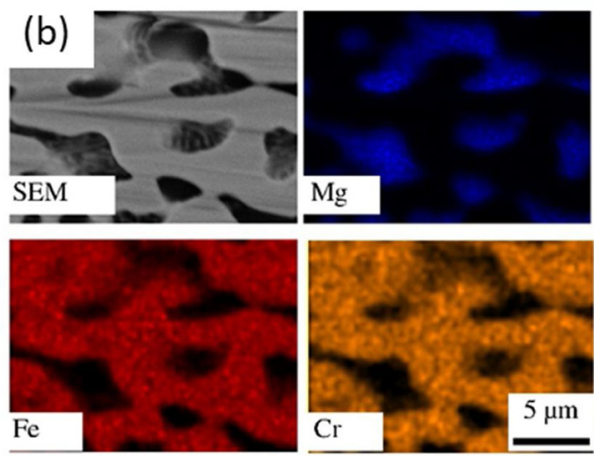

(d)
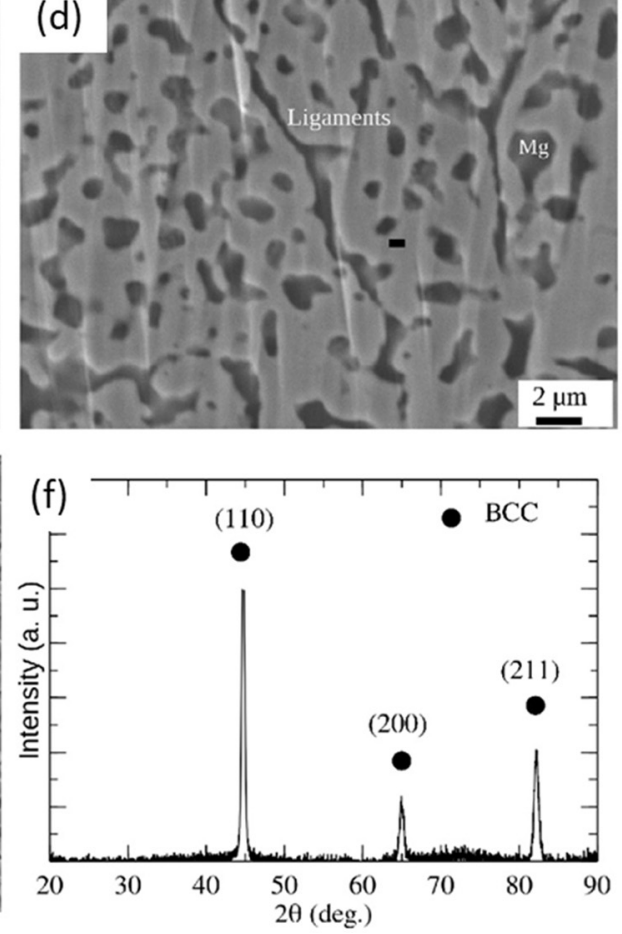

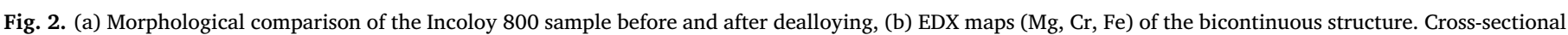

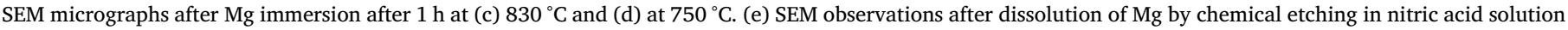

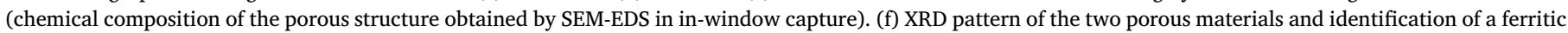
stainless steel phase.

porous stainless steel structures presents a bcc crystal lattice (Fig. 2(f)). On XRD diagram, no sigma phase was detected despite the high $\mathrm{Cr}$ content. This chemical composition associated to bcc crystal structure is close to commercial stainless steels such as SUS447J1 stainless steel making them porous alloys with several industrial applications [48].

In this work, the relation between the temperature of liquid $\mathrm{Mg}$ bath and the size of the ligaments follows the same trend that described by Wada et al. [28] and Tsuda et al. [49]: higher the temperature, larger the ligaments will be. For Incoloy 800 , an increase of $80^{\circ} \mathrm{C}$ of the bath temperature enhances about 2.5 times the average ligament size and average pore size (Table 2). However, the ligament and pore sizes remain significantly lower after $1 \mathrm{~h}$ of immersion than those obtained after dealloying a labmade precursor (Table 2) [34]. The main difference between the commercial Incoloy 800 and the labmade product stays in the presence of minor alloying elements as Ti or Si (respectively 0.6 at $\%$ and 0.8 at $\%$ in FCC phase in the precursor). As suspected with the absence of porosity control on Incoloy 825 , the presence of alloying elements in the precursor plays a negative role in the pores and ligaments size. In the mechanism of dealloying in liquid $\mathrm{Mg}$ bath, the $\mathrm{Ni}$ dissolution at the dealloying front requires surface diffusion of the remaining $\mathrm{Fe}, \mathrm{Cr}$, and minor elements if applicable [28]. Table 1 gave the mixing enthalpy energies of different metallic element with $\mathrm{Mg}$. If diffusion of $\mathrm{Si}$ in $\mathrm{Mg}$ phase is expected thermodynamically, the higher negative enthalpy for Fe suggests that it will remain in the stainless

Table 2

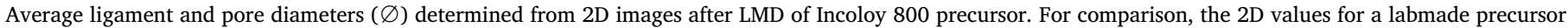
dealloyed under similar conditions in a previous study [34] are also provided.

\begin{tabular}{|c|c|c|c|}
\hline & Incoloy 800 LMD $1 \mathrm{~h} @ 830^{\circ} \mathrm{C}$ & Incoloy 800 LMD $1 \mathrm{~h} @ 750^{\circ} \mathrm{C}$ & $\left(\mathrm{Fe}_{80} \mathrm{Cr}_{20}\right)_{70} \mathrm{Ni}_{30} \mathrm{LMD} 1 \mathrm{~h} @ 820^{\circ} \mathrm{C}$ [34] \\
\hline Average ligament $\varnothing$ & $2.5 \pm 1.0 \mu \mathrm{m}$ & $1 \pm 0.2 \mu \mathrm{m}$ & $\sim 4 \mu \mathrm{m}$ \\
\hline Average pore size $\varnothing$ & $1.3 \pm 0.5 \mu \mathrm{m}$ & $0.5 \pm 0.1 \mu \mathrm{m}$ & $\sim 2.4 \mu \mathrm{m}$ \\
\hline
\end{tabular}


steel ligaments and slow down the dealloying rate resulting in smaller ligaments [36]. Further investigations should be performed on this point to better understand the effect of each elements on that process.

\subsection{Passive film composition: role of $\mathrm{Mg}$ dissolution in nitric acid solution}

In LDM technology, the porous materials are obtained after dissolution of the Mg-Ni phase in nitric acid solution. Since this occurs under the natural diffusion of nitric acid, stainless steel ligaments are in contact with the aggressive solution for at least $16 \mathrm{~h}$ at the surface of the foam and for shorter times in the volume. For Wallinder et al. [46], the corrosion resistance of a stainless steel increases after a nitric acid immersion. This was attributed to a $\mathrm{Cr}$ enrichment at the metal surface. These authors also noted that the nitric acid concentration, treatment time, and temperature had greater effects on the passive film thickness than on the $\mathrm{Cr}$ content in the film. Therefore, the use of the nitric acid solution in LMD process has two consequences: (i) to dissolve the Mg-Ni phase and to reveal the porous microstructure and (ii) to perform a passivation treatment on the stainless steel surface. Instead of to describe the passive film on porous materials, ingots with the same chemical composition were used for XPS analysis. This solution was preferred to limit the contribution of $\mathrm{Mg}-\mathrm{Ni}$ phase oxide on the bicontinuous microstructure (before nitric acid treatment) and to avoid roughness contribution on the metallic foam (after nitric acid treatment). According to [46], the chemical composition of the oxide film on our foam may be constant in surface and volume whereas its thickness should change from the extern to intern part of the sample due to different time of exposure to nitric acid. Note that further experiments are required to fully valid this assumption and also to differentiate the thickness evolution of the passive layer in the foam since the diffusion/ convection of species in the foam may affect the chemical etching efficiency.

Fig. 3 shows the XPS windows scans for Fe 2p, Cr 2p, and $\mathrm{O} 1 \mathrm{~s}$ recorded on the ingots before chemical etching and after the passivation treatment (limited to $1 \mathrm{~h}$ ). On both conditions, metallic elements and oxidized species coexist. For iron, the metallic state is located at $706.9 \mathrm{eV}$ whereas the broad peak at $710.2 \mathrm{eV}$ is attributed to iron oxide Fe (II). No clear identification was achieved in the Fe (II) to distinguish the hydroxyl species to oxide. For chromium, the metallic peak $\mathrm{Cr}(0)$ and the oxide peak $\mathrm{Cr}$ (III) are located at $573.9 \mathrm{eV}$ and $575.7 \mathrm{eV}$, respectively. In addition, an hydroxide peak $\mathrm{Cr}(\mathrm{III})$ is also identified at $577.1 \mathrm{eV}$. According to the database, the peak positions of $\mathrm{Cr}$ (III) refer to $\mathrm{Cr}_{2} \mathrm{O}_{3}$ at $575.7 \mathrm{eV}$ and $\mathrm{Cr}(\mathrm{OH})_{3}$ at $577.1 \mathrm{eV}$ [45]. The presence of the oxide-hydroxide layer is confirmed by the identification of $\mathrm{OH}^{-}$groups and $O$ in the oxide state in the oxygen spectrum. After nitric acid etching, the oxygen peak shows an increase of the oxide contribution as confirmed by the increase of the oxide contribution in chromium peak in Fig. 3(b). The chromium contents in the passive films were evaluated with Eq. (1). (Cr) ratio is approximately $41 \%$ without nitric acid treatment and increased to up to $67 \%$ after $1 \mathrm{~h}$ of immersion in the acidic solution. Before passivation, the oxide layer is at about $1.2 \mathrm{~nm}$ and it increases to $1.5 \mathrm{~nm}$ after immersion in nitric acid solution. Thus, the increase of $(\mathrm{Cr})_{\text {ratio }}$ and the oxide thickness strongly suggest a better corrosion resistance for the metallic foam than the bicontinuous microstructure [46]. Note that the comparison of corrosion resistance performances between the metallic foam and the precursor materials are out of scope here.

\subsection{Corrosion properties}

Fig. 4 presents the OCP, the polarization curves and the impedance spectroscopy diagram of ingots in absence or presence of passivation treatment. Whatever the sample, OCP curves stabilize at about -0.45 $\mathrm{V}_{\mathrm{MSE}}$ after $1000 \mathrm{~s}$ in the electrolyte. PEIS diagrams recorded after $1 \mathrm{~h}$ of immersion show the polarization resistance increase with the passivation treatment. The Nyquist diagrams in Fig. 4(c) contain only one pseudo capacitive loop. An equivalent electrical circuit was then used to model the passive film/electrolyte interface for the two samples (Fig. 6(a)). In this circuit, $R_{e}$ is the electrolyte resistance and the time constant $(\mathrm{R} / / \mathrm{CPE})$ is associated to the passive film response where $\mathrm{R}_{a}$ is the polarization resistance, and $\mathrm{Q}_{\mathrm{a}}$ is a Constant Phase Element (CPE, Eq. (3)). The use of a CPE (defined by $Q_{a}$ and $n_{a}$ ) instead of an ideal capacitor $\left(\mathrm{C}_{\mathrm{a}}\right)$ was imposed by the surface heterogeneities (roughness, charge distribution) and the cylindrical geometry of the ingots [50].

$Z(f)_{C P E}=\left[Q_{a} \cdot(2 \pi f)^{\mathrm{n}_{a}}\right]^{-1}$ (a)

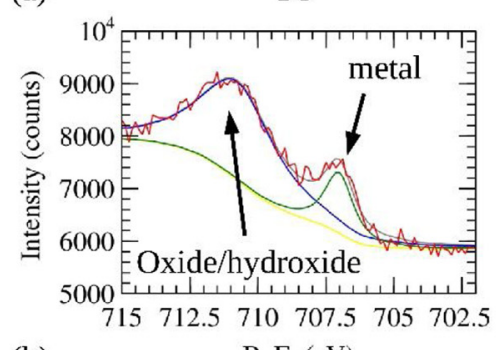

(b)

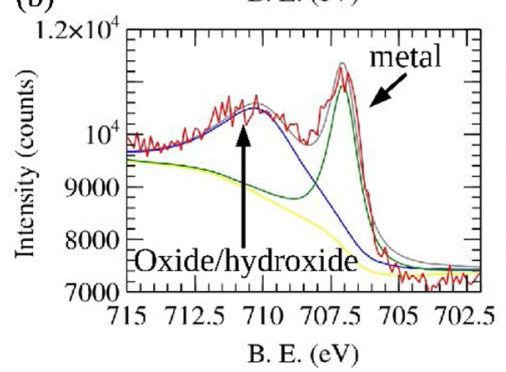

$\mathrm{Fe}$
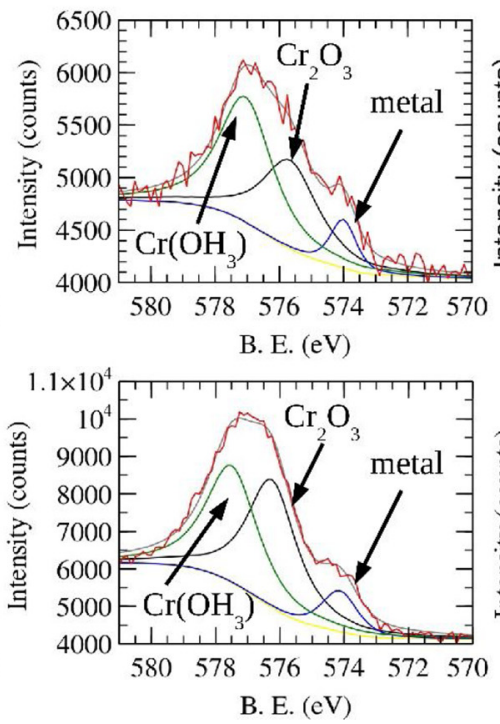
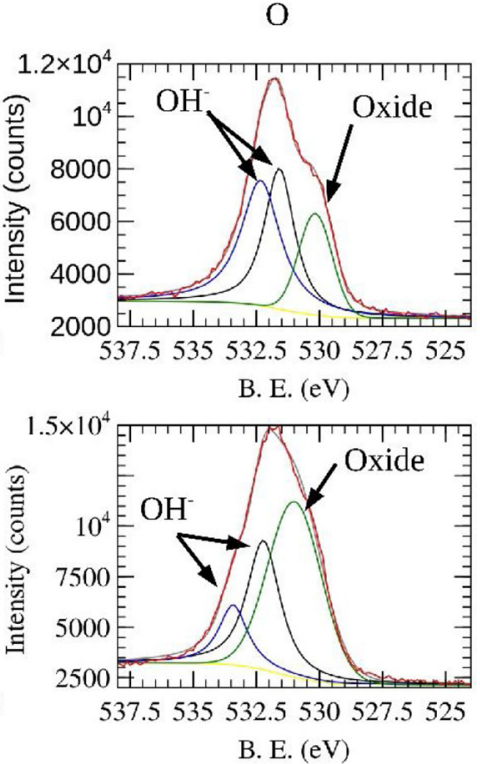

- Raw - Fit Background

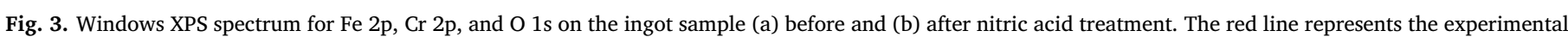

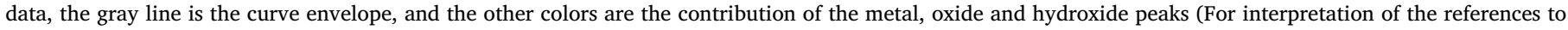
colour in this figure legend, the reader is referred to the web version of this article). 

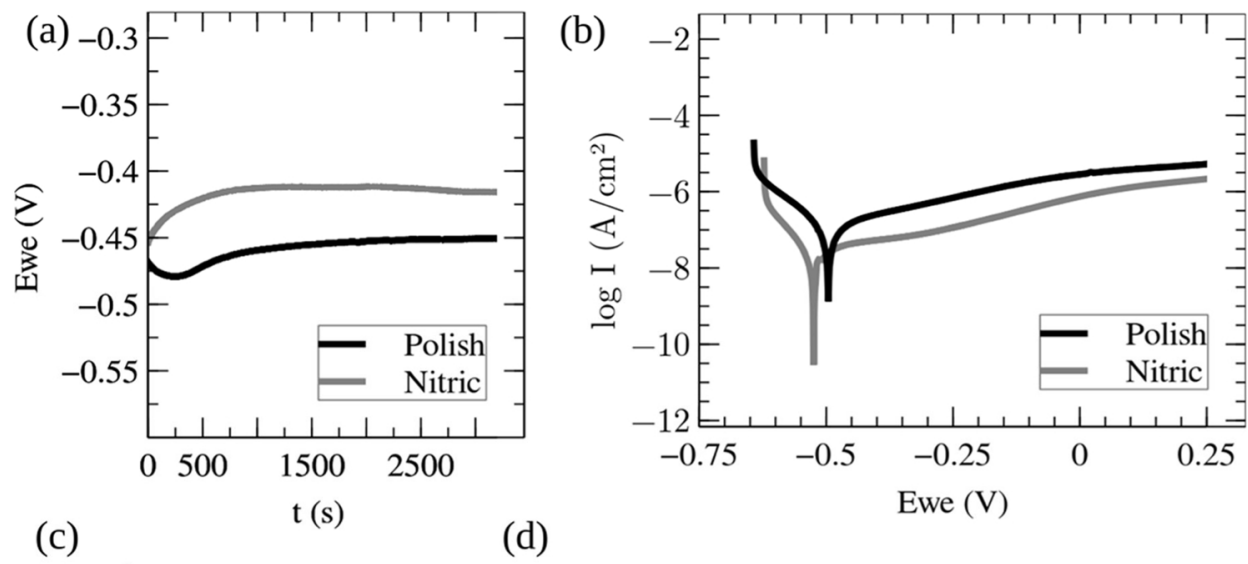

Fig. 4. (a) OCP curves, (b) LSV curves, (c) Nyquist diagram, and (d) Bode diagram recorded in aerated and stagnant $0.1 \mathrm{M} \mathrm{NaCl}$ solution at room temperature to understand the effect of acid nitric treatment on corrosion resistance. Experiments performed on ingot sample (bulk sample with the same composition as samples obtained after LMD and etching (i.e. $\left(\mathrm{Fe}_{67.7} \mathrm{Cr}_{29.5} \mathrm{Ti}_{1.0} \mathrm{Si}_{1.8}\right)$ ).
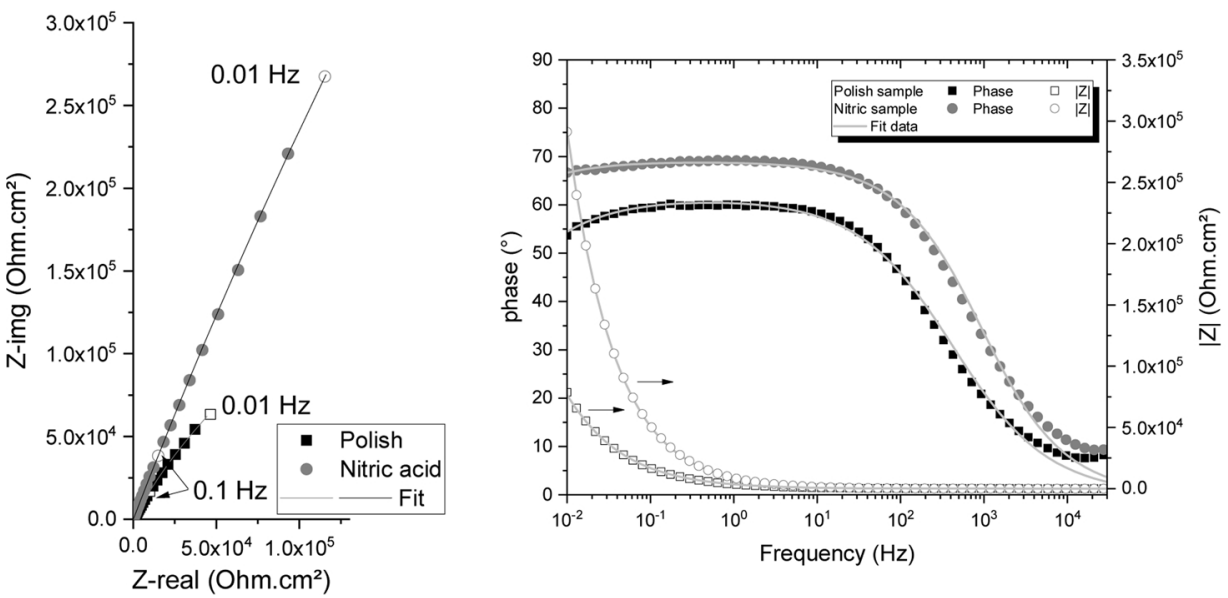

$\frac{1}{2 \pi\left(R_{a} \cdot \mathrm{Q}_{a}\right)^{1 / \mathrm{n}_{a}}}=\frac{1}{2 \pi \mathrm{R} \cdot \mathrm{C}_{a}}$

The fit results in Table 3 show a decrease of $Q_{a}$ with an increase of $\mathrm{n}_{\mathrm{a}}$ after the ingot passivation. Pseudo-capacitances calculated with Eq. (4) are equal of $475 \mu \mathrm{F} . \mathrm{cm}^{2}$ and $145 \mu \mathrm{F} . \mathrm{cm}^{2}$ for the polished and passivated surface, respectively and are proportional to the space charge capacitance and the double layer capacitance (Table 3). These values are somehow higher than the usual one for stainless steel passive film because of the cylindrical shape of the samples and also the roughness induced by SiC1200 polishing [64]. However, the decrease of the pseudo capacitances with the passivation treatment confirms the enhancement of the oxide properties as detected previously on XPS spectrum by the $\mathrm{Cr}$ enrichment of the surface and also in terms of stabilization of defects [51]. Further experiments are planned to determine the modification of the number of defects and identify the presence of a p-type or n-type capacitor based on Mott-Schottky analysis. Here, the most explicit parameter is $R_{a}$, which increased 10 times after the nitric acid treatment and is directly linked to the chromium content in the passive film (Fig. 4(d)). Consequently, the current in the passive region on polarization curves (Fig. 4(b)) decreases as less energy is required to maintain the passivity state in presence of a strong chromium oxide layer.

The porous materials were characterized in the same way as the ingots. OCP are slightly more anodic than those of the ingot materials (Fig. 5(a)). This nobler behavior was also observed on the corrosion potentials on potentiodynamique curves in Fig. 5(b). This may come from the longer passivation treatment that enhances the passive film properties as the morphology difference between the samples. However, polarization curves in Fig. 5(b) show the decrease of the corrosion resistance of the porous microstructures with the detection of localized corrosion initiation at approximately $0.25 \mathrm{~V}_{\mathrm{MSE}}$ irrespective of the pore size. The effects of the porosity on the surface reactivity are also detected on PEIS diagrams (Fig. 5(c)). For the two metallic foams, the spectrum presents a slope at approximately $45^{\circ}$ in the high frequency domain. In addition, a second slope at $45^{\circ}$ is detected on the $1.3 \mu \mathrm{m}$ pore sample at low frequency. Note that the amplitude of the spectrum

Table 3

Impedance fitting parameters for polished or passivated ingots and porous materials. The fit quality criterion is given by $\chi^{2} /|\mathrm{Z}|$ (lower it is, better the fit will be) and were lower than 0.53.

\begin{tabular}{|c|c|c|c|c|c|c|c|c|c|c|c|}
\hline \multirow[t]{2}{*}{ Sample } & \multirow{2}{*}{$\begin{array}{l}\mathrm{Re} \\
( \pm 10) \\
\Omega . \mathrm{cm}^{2}\end{array}$} & \multicolumn{5}{|l|}{$\mathrm{Z}_{\mathrm{c}}=\mathrm{Z}_{\mathrm{pore}, \mathrm{F}}$} & \multicolumn{5}{|l|}{$\mathrm{Z}_{\mathrm{a}}=(\mathrm{R} / / \mathrm{CPE})_{\mathrm{a}}$} \\
\hline & & $\begin{array}{l}\mathrm{Q}_{\mathrm{p}}\left( \pm 0.1 \times 10^{-4}\right) \\
\mathrm{F} . \mathrm{s}^{\mathrm{a}-1} \cdot \mathrm{cm}^{-2}\end{array}$ & $\begin{array}{l}\mathrm{n}_{\mathrm{p}} \\
( \pm 0.05)\end{array}$ & $\begin{array}{l}\mathrm{R}_{\mathrm{ct}, \mathrm{p}} \\
( \pm 20) \\
\Omega . \mathrm{cm}^{2}\end{array}$ & $\begin{array}{l}\mathrm{R}_{\text {ion, }} \\
\left( \pm 1 \times 10^{4}\right) \\
\Omega . \mathrm{cm}^{2}\end{array}$ & $\begin{array}{l}C_{p} \\
( \pm) \\
\mu F \cdot \mathrm{cm}^{-2}\end{array}$ & $\begin{array}{l}\mathrm{Q}_{\mathrm{a}} \\
\left( \pm 5 \times 10^{-8}\right) \\
\mathrm{F} \cdot \mathrm{s}^{\mathrm{a}-1} \cdot \mathrm{cm}^{-2}\end{array}$ & $\begin{array}{l}\mathrm{n}_{\mathrm{a}} \\
( \pm 0.05)\end{array}$ & $\begin{array}{l}\mathrm{R}_{\mathrm{a}}\left( \pm 1 \times 10^{4}\right) \\
\Omega . \mathrm{cm}^{2}\end{array}$ & $\begin{array}{l}\text { W } \\
\left( \pm 1 \times 10^{4}\right) \\
\Omega . \mathrm{s}^{0.5} \cdot \mathrm{cm}^{2}\end{array}$ & $\begin{array}{l}\mathrm{C}_{\mathrm{a}} \\
( \pm) \\
\mu \mathrm{F} \cdot \mathrm{cm}^{-2}\end{array}$ \\
\hline Polished ingots & 57 & - & - & - & & & $80 \times 10^{-6}$ & 0.68 & $55 \times 10^{4}$ & - & 475 \\
\hline Passivated ingots & 45 & - & - & - & & & $28 \times 10^{-6}$ & 0.76 & $658 \times 10^{4}$ & - & 145 \\
\hline $1.3 \mu \mathrm{m}$ pores & 6500 & $1.3 \times 10^{-4}$ & 0.72 & 504 & $12.4 \times 10^{-4}$ & 49 & $4.2 \times 10^{-6}$ & 0.85 & $19 \times 10^{4}$ & $7.2 \times 10^{4}$ & 4.1 \\
\hline $0.5 \mu \mathrm{m}$ pores & 420 & $0.9 \times 10^{-4}$ & 0.85 & 308 & $7.5 \times 10^{-4}$ & 44 & $0.36 \times 10^{-6}$ & 0.99 & $5.5 \times 10^{4}$ & - & 0.35 \\
\hline
\end{tabular}



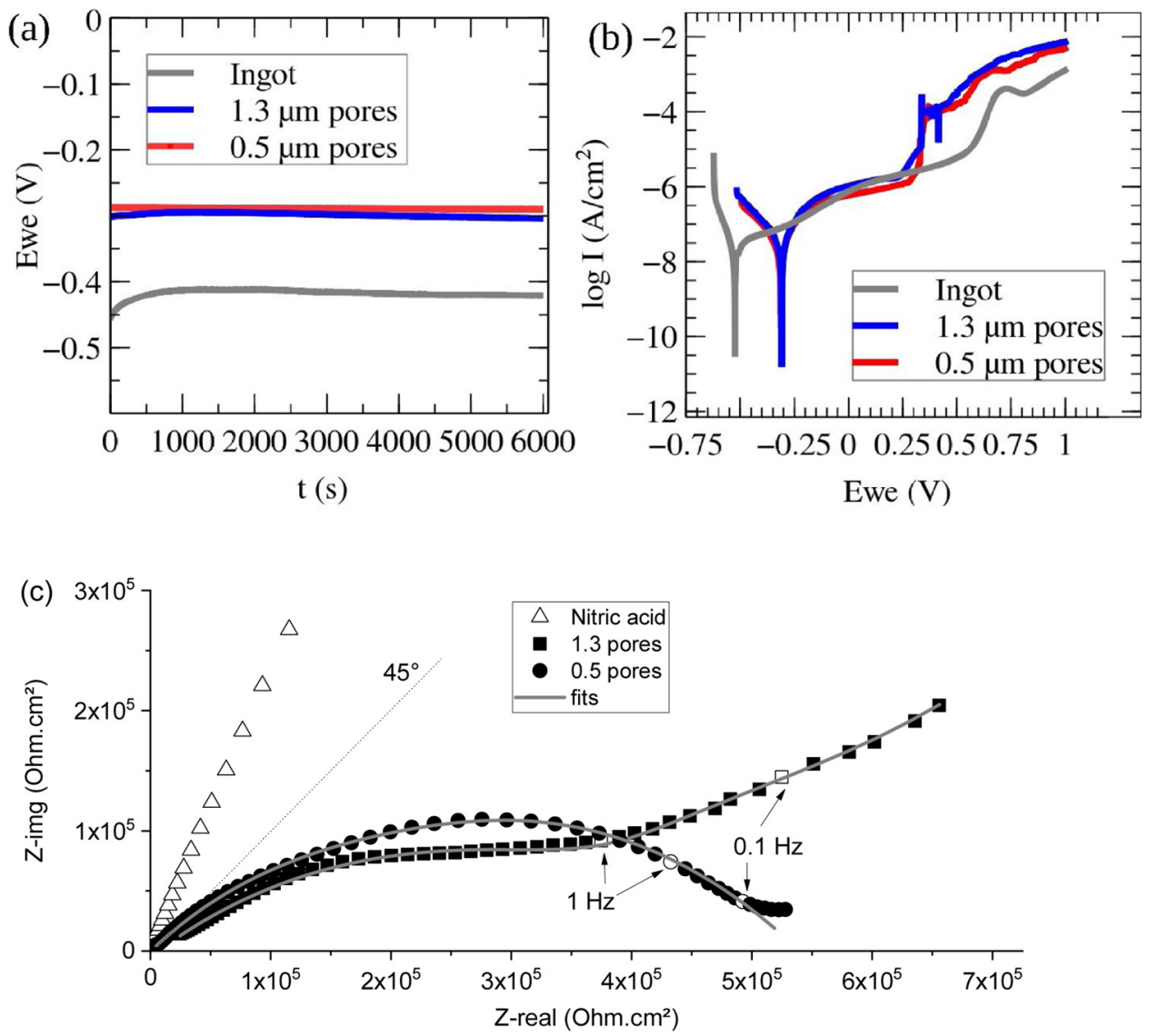

Fig. 5. (a) OCP curves (b) LSV curves, and (c) PEIS curves on bulk and porous samples. Experiments were realized on ingot sample after nitric acid treatment (ingot) and on porous samples with a pore size of $1.3 \mu \mathrm{m}$ and $0.5 \mu \mathrm{m}$. Measurements in aerated and stagnant $0.1 \mathrm{M} \mathrm{NaCl}$ solution (room temperature).
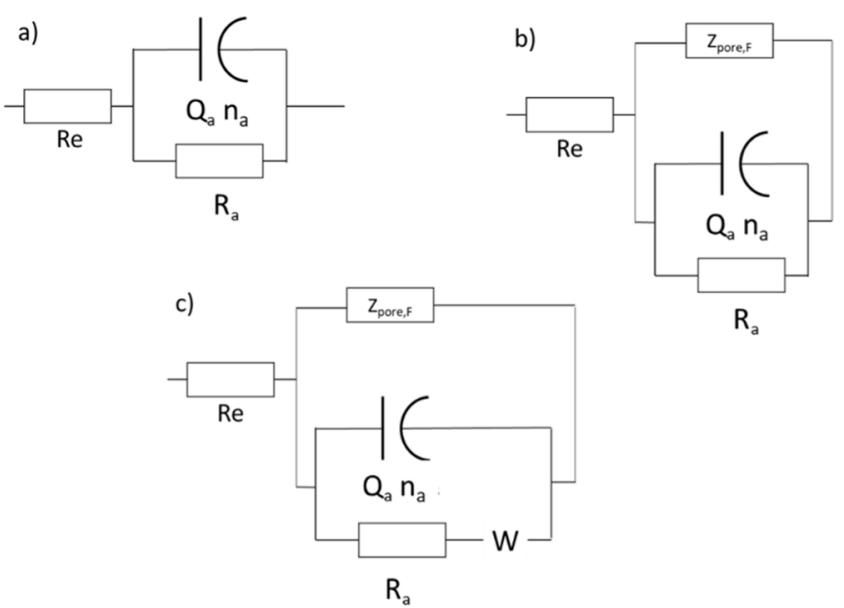

Fig. 6. Electrical models for a) the polished and the passivated rod, b) the $0.5 \mu \mathrm{m}$ pore sample and c) the $1.3 \mu \mathrm{m}$ pore specimen.

are lower than for plain samples which is online with the polarization curves that indicated a higher surface reactivity.

The high frequency impedance slope at $\sim 45^{\circ}$ is characteristic to porous materials and can fluctuate between $22^{\circ}$ and $45^{\circ}$ according to the defect properties [56,57]. Simulation of porous samples have been proposed by Keiser et al. [54] and latter De Levie et al. [55] who used a transmission line model. In their works they considered cylindrical semi-infinite, not connected and parallel pores (Eq. (5)) [53,60,62].

$Z_{\text {pore }, n F}=\sqrt{\frac{R_{\text {ion }, p}}{j \omega \cdot C_{p}, 2 \cdot \pi \cdot r}} \cdot \operatorname{coth}\left(L \cdot \sqrt{R_{i o n, p} \cdot \omega \cdot C_{p} \cdot 2 \cdot \pi \cdot r .}\right)$
Where $R_{\text {ion,p }}$ is the ionic resistance per unit of pore $\left(\Omega . \mathrm{cm}^{-1}\right), C_{p}$ is the electric double layer capacitance $\left(\mathrm{F} . \mathrm{cm}^{2}\right), r$ is the pore radius $(\mathrm{cm}), \mathrm{L}$ is the pore length $(\mathrm{cm})$.

The transmission line was then modified to account the pore size distribution on the impedance in absence of diffusion [58,59]. Barcia et al. [60] attended to quantify the characteristic length and radius as well as the number of independent pores. They highlighted that the number of pores and their average radius cannot be determined for semi-infinitely deep defects [61]. In addition to geometrical considerations, the surface reactivity of the pore walls has also to be considered and faradic processes $\left(\mathrm{Z}_{\text {pore,F}}\right.$, Eq. (6)) can occur and consequently modify the impedance of cylindrical pores given by the transmission line model [63].

$$
\begin{aligned}
Z_{p o r e, F}= & \sqrt{\frac{R_{\text {ion }, p} \cdot R_{c t, p}}{\left(1+j \omega \cdot R_{c t, p} \cdot C_{p} \cdot\right) 2 \cdot \pi \cdot r}} . \\
& \operatorname{coth}\left(L . \sqrt{\frac{R_{\text {ion }, p} \cdot\left(1+j \omega \cdot R_{c t, p} \cdot C_{p} \cdot\right) 2 \cdot \pi \cdot r}{R_{c t, p}}}\right)
\end{aligned}
$$

Where $R_{c t, p}$ is the pore charge transfer resistance $\left(\Omega . \mathrm{cm}^{-1}\right)$ while the other parameters were defined in Eq. (5).

In Eqs. (5) and (6), the capacitance $C_{p}$ can be replaced by the constant phase element defined by $Q_{p}$ and $n_{p}$ in the case of a non-ideal surface as previously done (Eq. (3)). Also, these two equations refer to the impedance of one pore which is assumed in first approximation for the two porous microstructures.

In this study, the structures are characterized by interconnected pores randomly oriented in the volume. The open represent at approximately $30 \%$ of the surface for the two samples (estimation based on ImageJ using a threshold calculation on Fig. 2(e)). Consequently, the 
oxide film on ligaments at the surface act on the definition of the material reactivity. At the corrosion potential, the overall impedance of stainless-steel porous samples is equivalent to the cathodic impedance in parallel to anodic impedance and in series with the solution resistance $\left(R_{e}\right)$. The cathodic impedance corresponds to pores contributions $\left(\mathrm{Z}_{\text {pore,F}}\right)$ while the anodic impedance is related to the space charge capacitance on the ligaments $\left(\mathrm{Q}_{\mathrm{a}}, \mathrm{n}_{\mathrm{a}}\right.$ or $\left.\mathrm{C}_{\mathrm{a}}\right)$ and the charge transfer resistance $\left(R_{a}\right)$ at the external surface of the samples [60]. In the case of the $1.3 \mu \mathrm{m}$ pore specimen, a Warburg $\mathrm{W}$ element was added to take into account the diffusion at low frequency.

Electrical equivalent circuits are schemed in Fig. 6(b) and (c) for the $1.3 \mu \mathrm{m}$ and $0.5 \mu \mathrm{m}$ pores samples respectively. In first approximation, the pore length, $\mathrm{L}$, is equal to the thickness of the two samples (i.e., $1 \mathrm{~mm}$ ) since this is the preferential dealloying orientation. The pore radius, $r$, corresponds to the values given in Table 2 for each material. Experimental and fitted Nyquist curves are plotted in Fig. 5(c) while Table 3 reports the fit results. The resistance of the electrolyte $\left(R_{e}\right)$ depends on the material structure. Compare to rod electrodes, $R_{e}$ is multiplied by 10 and 100 for $0.5 \mu \mathrm{m}$ and $1.3 \mu \mathrm{m}$ porous samples, respectively. This enhancement with the pore sizes is attributed to the modification of the contact number and surface between the ligaments since all the experiments were performed in the same solution. Therefore, having larger pores reduces the contact surface between ligaments and contributes to the increase of $R_{e}$ [54]. The ionic resistance $R_{i o n, p}$ depends on the porosity design and the largest pores lead to the highest resistance. This results is somehow surprising as $R_{\text {ion,p }}$ should increase with the pore length [63]. This finding has to be linked to the detection of Warburg impedance at low frequency for the $1.3 \mu \mathrm{m}$ pore sample. Indeed, the ionic resistance in Eq. (6) was defined originally for linear pores which is not the case here. The tortuosity of the pores and the ratio between the reservoir mouth and body affects the diffusion of species. Therefore, the volume of pores for the $1.3 \mu \mathrm{m}$ samples is higher and the diffusion of species is easier. In the case of the $0.5 \mu \mathrm{m}$ sample, the smaller ionic resistance comes from a more compact structure at the scale of the species diffusion as also supported by a greater value of for $\mathrm{n}_{\mathrm{p}}(0.85$ for $0.5 \mu \mathrm{m}$ and 0.72 for $1.3 \mu \mathrm{m}$ samples). The estimation of the pore capacitance from $Q_{p}, n_{p}$ and $R_{c t, p}$ (Eq. (4)) gives $49 \mu \mathrm{F} . \mathrm{cm}^{2}$ and 44 $\mu \mathrm{F} . \mathrm{cm}^{2}$ for $0.5 \mu \mathrm{m}$ and $1.3 \mu \mathrm{m}$ pore sizes, respectively. These values are in the order of magnitude of the double layer capacitance and does not change with the dimension of the pores. $R_{\text {ct,pore }}$ is almost constant whatever the electrode (Table 3). This means that the physical properties of the pore walls are independent to the porosity size. As previously mentioned, the reactivity of the outer part of the ligaments has also to be consider since it represents $\sim 70 \%$ of the outer surface of the sample. This is approximated by R//CPE and RW//CPE circuits for the small and large pore samples, respectively. The capacitance of the external surface of the samples is estimated with Eq. (4) considering $Q_{a}, n_{a}$ and $R_{a}$ (Table 3). The capacitance $C_{a}$ (Eq. (4)) decreases with the pore shrinkage $\left(4.1 \mu \mathrm{F} . \mathrm{cm}^{-2}\right.$ and $0.35 \mu \mathrm{F} . \mathrm{cm}^{-2}$ for large and small pores respectively). Actually, the value of $\mathrm{C}_{\mathrm{a}}$ corresponds to the space charge capacity in the case of large pores. However, $\mathrm{C}_{\mathrm{a}}$ spreads to the usual values for the $0.5 \mu \mathrm{m}$ sample which suggests that the oxide film is under the influence of the submicrometric pores and their effect on the local chemistry of the solution. The pore dimensions influence also $R_{c t, s}$ where tiny holes lead to a lower resistance. The use of the transmission line model enabled to distinguish the two porous structures in terms of surface reactivity. However, further microstructural analyses are required to describe better the pore interconnection in the volume, the tortuosity of the diffusion paths. Indeed, Cooper al. demonstrated that impedances for open systems with reservoir geometries deviate from the classical cylindrical pore model (see Fig. 2 in [53]).

\section{Conclusions}

In this paper, liquid metal dealloying (LMD) was applied on a commercial Incoloy 800 to create a stainless steel foam.
Microstructural, surface analyses and electrochemical characterizations were performed to evaluate the metallurgical properties of the stainless foam generated by this process. Mains results are summarized as follow:

- Porosity size depends on the temperature of the liquid metal bath. Higher the temperature is, bigger the ligament size and the porosities will be. However, this is not strongly modifying the porosity ratio.

- In comparison to pure precursor, the presence of minor alloying elements in Incoloy 800 has effect on the foam ligament size and porosity.

- The Mg phase etching by nitric acid solution leads to a Cr enrichment of the passive film that improves the corrosion resistance of the porous material.

- Pores increase the sensitivity to localized corrosion. However, no effect of the pore size on the pitting sensitivity was detected.

- Diffusion processes in the metallic foam have been detected for the sample with the highest porosity size.

Finally, our results demonstrate the potential of the LMD process to inexpensively produce free-standing fully porous ferritic stainless steel for use as selective membranes and for structural and functional products such as electrodes, supports, filters, etc.

\section{Declaration of interests}

The authors declare that they have no known competing financial interests or personal relationships that could have appeared to influence the work reported in this paper.

\section{Data availability statement}

The raw/processed data required to reproduce these findings cannot be shared at this time due to technical or time limitations.

\section{Acknowledgements}

This work was supported by ICC-IMR (Tohoku University, Japan), Région Rhone-Alpes [CMIRA 138249], the Erasmus + program, and the French Ministry of Research.

\section{Appendix A. Supplementary data}

Supplementary material related to this article can be found, in the online version, at doi:https://doi.org/10.1016/j.corsci.2020.108468.

\section{References}

[1] J. Erlebacher, R. Seshadri, Hard materials with tunable porosity, MRS Bull. 34 (2009) 561-568, https://doi.org/10.1557/mrs2009.155.

[2] J. Snyder, T. Fujita, M. Chen, J. Erlebacher, Oxygen reduction in nanoporous metal-ionic liquid composite electrocatalysts, Nat. Mater. 9 (2010) 904-907, https:// doi.org/10.1038/nmat2878.

[3] X.Y. Lang, A. Hirata, T. Fujita, M. Chen, Nanoporous metal/oxide hybrid electrodes for electrochemical supercapacitors, Nat. Nanotechnol. 6 (2011) 202-206, https:// doi.org/10.1038/nnano.2011.13.

[4] L.Y. Chen, J.S. Yu, T. Fujita, M. Chen, Nanoporous copper with tunable nanoporosity for SERS applications, Adv. Funct. Mater. 19 (2009) 1221-1226, https:// doi.org/10.1002/adfm.200801209.

[5] Y. Fukuzumi, T. Wada, H. Kato, Surface improvement for biocompatibility of Ti6Al-4V by dealloying in metallic melt, in: K. Sasaki, O. Suzuki, N. Takahashi (Eds.), Interface Oral Health Science, Springer, 2016, pp. 93-101.

[6] H. Kato, T. Wada, M. Sadeghilaridjani, Dealloying toxic Ni from SUS316L surface, in: K. Sasaki, O. Suzuki, N. Takahashi (Eds.), Interface Oral Health Science, Springer, 2016, pp. 35-46.

[7] I.V. Okulov, J. Weissmüller, J. Markmann, Dealloying-based interpenetrating-phase nanocomposites matching the elastic behavior of human bone, Sci. Rep. 20 (7) (2017) 1-7, https://doi.org/10.1038/s41598-017-00048-4.

[8] I.V. Okulov, A.V. Okulov, I.V. Soldatov, B. Luthringer, R. Willumeit-Römer, T. Wada, H. Kato, J. Weissmüller, J. Markmann, Open porous dealloying-based biomaterials as a novel biomaterial platform, Mater. Sci. Eng. C 88 (2018) 95-103, https://doi.org/10.1016/j.msec.2018.03.008. 
[9] A.V. Okulov, A.S. Volegov, J. Weissmüller, J. Markmann, I.V. Okulov, Dealloyingbased metal-polymer composites for biomedical applications, Scri. Mater. 146 (2018) 290-294, https://doi.org/10.1016/j.scriptamat.2017.12.022.

[10] I.V. Okulov, A.V. Okulov, A.S. Volegov, J. Markmann, Tuning microstructure and mechanical properties of open porous TiNb and TiFe alloys by optimization of dealloying parameters, Scri. Mater. 154 (2018) 68-72, https://doi.org/10.1016/j. scriptamat.2018.05.029.

[11] Y. Ding, J. Erlebacher, Nanoporous metals with controlled multimodal pore size distribution, J. Am. Chem. Soc. 125 (26) (2003) 7772-7773, https://doi.org/10. 1021/ja035318g.

[12] L.F. Dumée, L. He, B. Lin, F.-M. Allioux, J.-B. Lemoine, L. Velleman, F. She, M.C. Duke, J.D. Orbell, G. Erskine, P. Hodgson, S. Gray, L. Kong, The fabrication and surface functionalization of porous metal frameworks -a review, J. Mater. Chem. A 48 (2013) 15185-15206, https://doi.org/10.1039/C3TA13240D.

[13] L. Dumée, K. Velleman, M. Sears, J. Hill, N. Schutz, M. Finn, S. Duke, Gray, control of porosity and pore size of metal reinforced carbon nanotube membranes, Membranes 1 (1) (2010) 25-36, https://doi.org/10.3390/membranes1010025.

[14] H. Wu, R. Zhang, X. Liu, D. Lin, W. Pan, Electrospinning of Fe, Co, and Ni nanofibers: synthesis, assembly, and magnetic properties, Chem. Mater. 19 (14) (2007) 3506-3511, https://doi.org/10.1021/cm070280i.

[15] S.C. Warren, L.C. Messina, L.S. Slaughter, M. Kamperman, Q. Zhou, S.M. Gruner, F.J. DiSalvo, U. Wiesner, Ordered mesoporous materials from metal nanoparticle-block copolymer self-assembly, Science 320 (2008) 1748-1752, https://doi. org/10.1126/science.1159950.

[16] S.H. Ko, J. Chung, N. Hotz, K.H. Nam, C.P. Grigoropoulos, Metal nanoparticle direct inkjet printing for low-temperature 3D micro metal structure fabrication, J. Micromech. Microeng. 20 (12) (2010), https://doi.org/10.1088/0960-1317/20/ $12 / 125010125010$

[17] A.J. Forty, Corrosion micromorphology of noble metal alloys and depletion gilding, Nature 282 (1979) 597-598, https://doi.org/10.1038/282597a0.

[18] C. Xu, Y. Li, F. Tian, Y. Din, Dealloying to nanoporous silver and its implementation as a template material for construction of nanotubular mesoporous bimetallic nanostructures, Chem. Phys. Chem 11 (2010) 3320-3328, https://doi.org/10.1002/ cphc. 201000313.

[19] D.V. Pugh, A. Dursun, S.G. Corcoran, Formation of nanoporous platinum by selective dissolution of Cu from Cu0.75Pt0.25, J. Mater. Res. 18 (2003) 216-221, https://doi.org/10.1557/JMR.2003.0030.

[20] U.S. Min, J.C.M. Li, The microstructure and dealloying kinetics of a Cu-Mn alloy, J. Mater. Res. 11 (1994) 2878-2883, https://doi.org/10.1557/JMR.1994.2878.

[21] J.R. Hayes, A.M. Hodge, J. Biener, A.V. Hamza, K. Sieradzki, Monolithic nanoporous copper by dealloying $\mathrm{Mn}-\mathrm{Cu}$, J. Mater. Res. 21 (2006) 2611-2616, https:// doi.org/10.1557/jmr.2006.0322.

[22] A.J. Smith, T. Tran, M.S. Wainwright, Kinetics and mechanism of the preparation of Raney ${ }^{\circledast}$ copper, J. Appl. Electrochem. 29 (1999) 1085-1094, https://doi.org/10. 1023/A:1003637410133.

[23] L. Sun, C.-L. Chien, P.C. Searson, Fabrication of nanoporous nickel by electrochemical dealloying, Chem. Mater. 16 (2004) 3125-3129, https://doi.org/10. $1021 / \mathrm{cm} 0497881$.

[24] S. Nam, H. Jo, H. Choe, D. Ahn, H. Choi, Development of nanoporous copper foams by chemical dealloying of mechanically alloyed Al-Cu compounds, Mater. Trans 55 (9) (2014), https://doi.org/10.2320/matertrans.M2014068 1414-141.

[25] L. Semiz, N. Abdullayeva, M. Sankir, Nanoporous Pt and Ru catalysts by chemical dealloying of Pt-Al and Ru-Al alloys for ultrafast hydrogen generation, J. Alloys. Compd. 744 (2018) 110-115, https://doi.org/10.1016/j.jallcom.2018.02.082.

[26] M. Sankir, L. Semiz, R.B. Serin, N.D. Sankir, Hydrogen generation from nanoflower platinum films, Int. J. Hydrog. Energy 40 (27) (2015) 8522-8529, https://doi.org/ 10.1016/j.ijhydene.2015.04.137.

[27] T. Wada, K. Yubuta, A. Inoue, H. Kato, Dealloying by metallic melt, Mater. Lett. 65 (2011) 1076-1078, https://doi.org/10.1016/j.matlet.2011.01.054.

[28] T. Wada, H. Kato, Three-dimensional open-cell macroporous iron, chromium and ferritic stainless steel, Scr. Mater. 68 (2013) 720-726, https://doi.org/10.1016/j. scriptamat.2013.01.011.

[29] J.W. Kim, T. Wada, S.G. Kim, H. Kato, Sub-micron porous niobium solid electrolytic capacitor prepared by dealloying in a metallic melt, Mater. Lett. 116 (2014) 220-226, https://doi.org/10.1016/j.matlet.2013.11.036.

[30] I.V. Okulov, S.V. Lamaka, T. Wada, K. Yubuta, M.L. Zheludkevich, J. Weissmuller, J. Markmann, H. Kato, Nanoporous magnesium, Nano Res. 11 (2018) 6428-6435, https://doi.org/10.1007/s12274-018-2167-9.

[31] A. Takeuchi, A. Inoue, Classification of bulk metallic glasses by atomic size difference, heat of mixing and period of constituent elements and its application to characterization of the main alloying element, Mater. Trans. 46 (2005) 2817-2829, https://doi.org/10.2020/matertrans.46.2817.

[32] D.M. Artymowicz, J. Erlebacher, R.C. Newman, Relationship between the parting limit for de-alloying and a particular geometric high-density site percolation threshold, Philos. Mag. 89 (2009) 1663-1693, https://doi.org/10.1080/ 14786430903025708.

[33] C. Zhao, T. Wada, V. De Andrade, G.J. Williams, J. Gelb, L. Li, J. Thieme, H. Kato, Y.-C.K. Chen-Wiegart, Three-dimensional morphological and chemical evolution of nanoporous stainless steel by liquid metal dealloying, ACS Appl. Mater. Interfaces 9 (39) (2017) 34172-34184, https://doi.org/10.1021/acsami.7b04659.

[34] M. Mokhtari, C. Le Bourlot, J. Adrien, A. Bonnin, T. Wada, J. Duchet-Rumeau, H. Kato, E. Maire, Microstructure Characterization by X-ray tomography and EBSD of porous FeCr produced by liquid metal dealloying, Mater. Charac. 144 (2018) 166-172, https://doi.org/10.1016/j.matchar.2018.06.032.

[35] M. Tsuda, T. Wada, H. Kato, Kinetics of formation and coarsening of nanoporous atitanium dealloyed with Mg melt, J. Appl. Phys. 114 (2013), https://doi.org/10. 1063/1.4821066 113503(1-8).

[36] M. Mokhtari, T. Wada, C. Le Bourlot, N. Mary, J. Duchet-Rumeau, H. Kato, E. Maire,
Low cost high specific surface architectured nanoporous metal with corrosion resistance produced by liquid metal dealloying from commercial nickel superalloy, Scr. Mater. 163 (2019) 5-8, https://doi.org/10.1016/j.scriptamat.2018.12.020.

[37] W. Liang, Y. Jiang, H. Dong, Y. He, N. Xu, J. Zou, B. Huang, C.T. Liu, The corrosion behavior of porous Ni3Al intermetallic materials in strong alkali solution, Intermetallics 19 (11) (2011) 1759-1765, https://doi.org/10.1016/j.intermet. 2011.06.016.

[38] G. Jia, C. Chen, J. Zhang, Y. Wang, R. Yue, B.J.C. Luthringer-Feyerabend, R. Willumeit-Roemer, H. Zhang, M. Xiong, H. Huang, G. Yuan, F. Feyerabend, In vitro degradation behavior of $\mathrm{Mg}$ scaffolds with three-dimensional interconnected porous structures for bone tissue engineering, Corros. Sci. 144 (2018) 301-312, https://doi.org/10.1016/j.corsci.2018.09.001.

[39] A. Al-Jarba, G.E. Fuchs, Effect of carbon additions on the as-cast microstructure and defect formation of a single crystal Ni-based superalloy, Mater. Sci. Eng. A 373 (2004) 255-267, https://doi.org/10.1016/j.msea.2004.01.030.

[40] R. Dehmolaei, M. Shamanian, A. Kermanpur, Microstructural changes and mechanical properties of Incoloy 800 after 15 years service, Mater. Charac. 60 (3) (2009) 246-250, https://doi.org/10.1016/j.matchar.2008.08.012.

[41] G. Sayiram, N. Arivazhagan, Microstructural characterization of dissimilar welds between Incoloy $800 \mathrm{H}$ and 321 austenitic stainless steel, Mater. Charac. 102 (2015) 180-188, https://doi.org/10.1016/j.matchar.2015.03.006.

[42] "Incoloy alloy $800 "$ ". Special metals. http://www.specialmetals.com/assets/smc/ documents/alloys/incoloy/incoloy-alloy-800.pdf, (accessed 2018-05-22).

[43] J. Schindelin, I. Arganda-Carreras, E. Frise, et al., Fiji: an open-source platform for biological-image analysis, Nat. Methods 9 (2012) 676-682, https://doi.org/10. 1038/nmeth.2019.

[44] Y.-C.K. Chen-Wiegart, T. Wada, N. Butakov, X. Xiao, F. De Carlo, H. Kato, J. Wang, D.C. Dunand, E. Maire, 3D morphological evolution of porous titanium by x-ray micro- and nano-tomography, J. Mater. Res. 28 (2013) 2444-2452, https://doi.org/ $10.1557 / \mathrm{jmr} .2013 .151$.

[45] La surface, http://www.lasurface.com/accueil/index.php (accessed 2018-09-22).

[46] D. Wallinder, J. Pan, C. Leygraf, A. Delblanc-Bauer, Eis and XPS study of surface modification of 316LVM stainless steel after passivation, Corro. Sci. 41 (2) (1998) 275-289, https://doi.org/10.1016/S0010-938X(98)00122-X.

[47] J.H. Han, D.Y. Kim, Analysis of the proportionality constant correlating the mean intercept length to the average grain size, Acta Metall. Mater. 43 (8) (1995) 3185-3188, https://doi.org/10.1016/0956-7151(95)00007-I.

[48] HongChao stainless steel, China http://www.cn-stainless-steel.com/Products/ ferritic_stainless_steel/SUS447J1-A143.htm (accessed 2018-11-25).

[49] M. Tsuda, Doctoral Thesis, Formation Mechanism of Porous Metals During Liquid Metal Dealloying Process, Doctoral Thesis, Tohoku University, Sendai, 2014 (in Japanese).

[50] O. Lavigne, C. Alemany-Dumont, B. Normand, P. Delichère, A. Descamps, Cerium insertion in 316L passive film: effect on conductivity and corrosion resistance performances of metallic bipolar plates for PEM fuel cell application, Surf. Coat. Tech. 205 (7) (2010) 1870-1877, https://doi.org/10.1016/j.surfcoat.2010.08.051.

[51] M.J. Carmezim, A.M. Simões, M.F. Montemor, M. Da Cunha Belo, Capacitance behaviour of passive films on ferritic and austenitic stainless steel, Corro. Sci. 47 (2005), https://doi.org/10.1016/j.corsci.2004.07.002 581-59.

[53] Samuel J. Cooper, Antonio Bertei, Donal P. Finegan, Nigel P. Brandon, Simulated impedance of diffusion in porous media, Electroch. Acta 251 (2017) 681-689, https://doi.org/10.1016/j.electacta.2017.07.152.

[54] H. Keiser, K.D. Beccu, M.A. Gutjahr, Abschätzung der porenstruktur poröser elektroden aus impedanzmessungen, Electroch. Acta 21 (8) (1976) 539-543, https:// doi.org/10.1016/0013-4686(76)85147-.X.

[55] R. De Levie, Electrochemical response of porous and rough electrodes, Adv. electrochem. and electrochem. Eng 6 (1967) 329-397.

[56] X.-Y. Wang, J. Yan, H.-T. Yuan, Y.-S. Zhang, D.-Y. Song, Impedance studies of nickel hydroxide microencapsulated by cobalt, Int. J. Hydrogen Energy 24 (10) (1999) 973-980, https://doi.org/10.1016/S0360-3199(98)00130-X.

[57] S.A.G.R. Karunathilaka, N.A. Hampson, R. Leek, T.J. Sinclair, The impedance of the alkaline zinc-manganese dioxide cell. I: variation with state of charge, J. Appl. Electrochem. 11 (3) (1981) 365-372, https://doi.org/10.1007/BF00613957.

[58] C. Hitz, A. Lasia, Experimental study and modeling of impedance of the her on porous Ni electrodes, J. Electroanal. Chem. 500 (1-2) (2001) 213-222, https://doi. org/10.1016/S0022-0728(00)00317-X.

[59] H.-K. Song, Y.-H. Jung, K.-H. Lee, L.H. Dao, Electrochemical impedance spectroscopy of porous electrodes: the effect of pore size distribution, Electroch. Acta 44 (20) (1999) 3513-3519, https://doi.org/10.1016/S0013-4686(99)00121-8.

[60] O.E. Barcia, E. D’Elia, I. Frateur, O.R. Mattos, N. Pébère, B. Tribollet, Application of the impedance model of de Levie for the characterization of porous electrodes, Electrochim. Acta 47 (13-14) (2002) 2109-2116, https://doi.org/10.1016/S00134686(02)00081-6.

[61] O.E. Barcia, S. Cattarin, E. D’Elia, I. Frateur, O.R. Mattos, M. Musiani, N. Pébère, B. Tribollet, Further to the paper "Application of the impedance model of de Levie for the characterization of porous electrodes" by Barcia et al, Electrochim. Acta 47 (2002) 2096-2097, https://doi.org/10.1016/j.electacta.2005.06.035.

[62] D. Cericola, M.E. Spahr, Impedance spectroscopic studies of the porous structure of electrodes containing graphite materials with different particle size and shape, Electrochim. Acta 191 (2016) 558-566, https://doi.org/10.1016/j.electacta.2016. 01.121.

[63] N. Ogihara, S. Kawauchi, C. okuda, Y. Itou, Y. Takeuchi, Y. Ukyo, Theoretical and experimental analysis of porous electrodes for lithium-ion batteries by electrochemical impedance spectroscopy using a symmetric cell, J. Electrochem. Soc. 159 (2012) A1034-A1039 http://jes.ecsdl.org/content/159/7/A1034.

[64] A. Fattah-alhosseini, Passivity of AISI 321 stainless steel in $0.5 \mathrm{M} \mathrm{H} 2 \mathrm{SO} 4$ solution studied by Mott-Schottky analysis in conjunction with the point defect model, Arab. J. Chem. 9 (2016) S1342-S1348, https://doi.org/10.1016/j.arabjc.2012.02.015. 